\title{
Comunicação
}

\section{Primeiro registro do besouro-amarelo-do-eucalipto em plantio de eucalipto no Estado do Acre ${ }^{1}$}

\author{
Rodrigo Souza Santos ${ }^{2 *}$, Roberto Gonçalves ${ }^{3}$, Norivaldo dos Anjos Silva ${ }^{4}$ \\ 10.1590/0034-737X201663040020
}

\begin{abstract}
RESUMO
A ocorrência do besouro-amarelo-do-eucalipto, Costalimaita ferruginea (Fabricius) (Coleoptera: Chrysomelidae), foi confirmada em plantio de Eucalyptus pellita F. Muell, Eucalyptus urophylla S. T. Blake e Eucalyptus camaldulensis Dehn., no município de Senador Guiomard, Acre. O ataque foi constatado com maior intensidade em E. pellita, seguido por E. urophylla e E. camaldulensis em menor intensidade. Este é o primeiro registro dessa espécie de besouro desfolhador, em eucaliptais cultivados no Estado, contribuindo assim para o aumento do conhecimento sobre a distribuição geográfica desse inseto na região amazônica, bem como no Brasil.
\end{abstract}

Palavras-chave: desfolhador de eucalipto; Chrysomelidae; Myrtaceae; Eucalyptus; silvicultura.

\section{ABSTRACT}

\section{First record of eucalyptus yellow beetle in eucalyptus plantation in the state of Acre, Brazil}

The occurrence of the Eucalyptus yellow beetle, Costalimaita ferruginea (Fabricius) (Coleoptera: Chrysomelidae), was reported in plantations of Eucalyptus pellita F. Muell, Eucalyptus urophylla S. T. Blake and Eucalyptus camaldulensis Dehn. in the municipality of Senador Guiomard, Acre, Brazil. The attack was verified with higher intensity in E. pellita, followed by E. urophylla and lower intensity in E. camaldulensis. This is the first record of this defoliator beetle species in eucalyptus plantations in this state, thus contributing to the increase in knowledge about the geographical distribution of this insect in the Amazon region, as well as in Brazil.

Key words: eucalyptus defoliator, Chrysomelidae, Myrtaceae, Eucalyptus, forestry.

\footnotetext{
Submetido em 12/02/2014 Aprovado em 23/02/2016.

Esta pesquisa foi realizada pela Embrapa Acre em parceria com a Empresa Floresta Desenvolvimento de Projetos Ltda.

${ }^{2}$ Embrapa Acre, Rio Branco, Acre, Brasil. rodrigo.s.santos@embrapa.br

${ }^{3}$ Floresta Desenvolvimento de Projetos Ltda., Rio Branco, Acre, Brasil. roberto@floresta.com

${ }^{4}$ Universidade Federal de Viçosa, Departamento de Biologia Animal, Viçosa, Minas Gerais, Brasil. nanjos@ufv.br

* Autor para correspondência: rodrigo.s.santos@embrapa.br
} 


\section{INTRODUÇÃO}

A eucaliptocultura, introduzida no Brasil no século $\mathrm{XX}$, tornou-se importante atividade econômica do país, ocupando área de aproximadamente 4,8 milhões de hectares (Abraf, 2012). A importância econômica do eucalipto (Eucalyptus L'Her, Myrtaceae) decorre do seu rápido crescimento, de sua capacidade produtiva, de sua adaptabilidade em diversos ambientes e, principalmente, da diversidade de espécies e híbridos, o que torna possível atender à demanda de grande parte dos segmentos que utilizam produtos florestais (Garlet et al., 2009), principalmente o setor de papel e celulose (Bacha \& Barros, 2004).

Com a expansão da área plantada, os problemas entomológicos dos eucaliptais aumentaram, visto que a monocultura de maciços florestais homogêneos também favorece a ocorrência e manutenção de altas populações de insetos daninhos nas árvores, por causa, sobretudo, da grande disponibilidade de alimento e da simplificação do ambiente (Altieri, 2003; Panizzi \& Parra, 2009), o que pode prejudicar o empreendimento florestal (Ohmart \& Edwards, 1991).

Entre os insetos associados à eucaliptocultura, relatam-se principalmente as formigas-cortadeiras, os besouros e as lagartas desfolhadores, seguidos por espécies que atacam as raízes, os broqueadores de tronco e os sugadores de seiva (Zanuncio et al., 1993; Santos et al., 2008; Costa et al., 2011), podendo assumir o status de pragas, dependendo do seu nível populacional.

\section{MATERIAL E MÉTODOS}

Em setembro de 2013, besouros foram encontrados alimentando-se de folhas de Eucalyptus pellita F. Muell, Eucalyptus urophylla S. T. Blake e Eucalyptus camaldulensis Dehn., cultivados na fazenda Camboré (10¹3’07.9" S; 67²4'33.5" O; $203 \mathrm{~m}$ de altitude), no município de Senador Guiomard, AC. A fazenda Camboré cultiva eucalipto em plantio extensivo e, no entorno dos talhões, há presença de pasto e de vegetação de capoeira.

A área em que foi registrada a presença do inseto corresponde a 3,0 ha, com espaçamento de 3,0 × 3,0 m entre árvores, plantas com nove meses de idade e altura aproximada de 3,2 m. Machos $(n=11)$ e fêmeas $(n=12)$ desses besouros foram coletados manualmente, diretamente nas folhas do terço inferior da copa, em árvores das três espécies, e acondicionados em frascos de vidro identificados. Esse material foi encaminhado ao Laboratório de Entomologia da Embrapa Acre, em Rio Branco, AC, onde foi submetido à triagem e montagem entomológica dos espécimes coletados.

\section{RESULTADOS E DISCUSSÃO}

Os insetos foram identificados como sendo os crisomelídeos Costalimaita ferruginea (Fabricius) (Coleoptera: Chrysomelidae), depositados na Coleção do Museu Regional de Entomologia (UFVB), em Viçosa, MG.

Os besouros desfolhadores constituem o terceiro grupo de insetos-praga mais relevantes para a silvicultura brasileira e sua importância vem crescendo, em função do crescimento de novos registros, principalmente na cultura do eucalipto (Montes et al., 2012). Coleópteros desfolhadores da família Chrysomelidae compõem um importante grupo de herbívoros associados a eucaliptos, particularmente em árvores jovens (Ohmart \& Edwards, 1991). Dentre os crisomelídeos, destaca-se C. ferruginea, como o principal besouro desfolhador do eucalipto, em virtude de sua voracidade e de seu potencial biótico (Santos et al., 2008), sendo conhecido, popularmente, por "besouro-amarelo-do-eucalipto" ou "vaquinha" (Gallo $e t$ al., 2002).

Em altos níveis populacionais, esse inseto promove intensa desfolha em árvores cultivadas, provocando a redução da capacidade fotossintética e o consequente atraso do seu crescimento e desenvolvimento (Mendes et al., 1998). Os adultos se alimentam das folhas, perfurando-as, deixando-as com um aspecto rendilhado. As folhas danificadas perdem água pelas bordas dos orifícios, sofrendo murcha e secamento (Costa et al., 2011).

O prejuízo é acentuado quando a gema apical (ponteiro) da planta também é atacada, sendo cortada pelos besouros, causando ramificações laterais nas árvores. $\mathrm{O}$ impacto do ataque do besouro sobre o crescimento inicial e a produção de eucaliptos aumenta com o decorrer do tempo, de acordo com a intensidade de desfolhamento provocado por diferentes níveis populacionais do inseto na área (Montes et al., 2012).

Além de espécies de eucalipto, $C$. ferruginea tem como plantas hospedeiras: abacateiro (Persea americana Mill.), algodoeiro (Gossypium sp.), araçazeiro (Psidium sp.), cajueiro (Anacardium occidentale L.), camu-camu [Myrciaria dubia (H.B.K.) McVaugh], goiabeira (Psidium guajava L.), jambeiro (Syzygium malaccense L.), jambolão (Syzygium cumini Lamarck), jabuticabeira [Myrciaria cauliflora (Mart.)], manacá [Tibouchina mutabilis (Vell.) Cogn.], macieira (Malus domestica Borkh), mangueira (Mangifera indica L.), pitangueira (Eugenia uniflora L.), araçá-domato (Psidium guineense Sw.), videira (Vitis vinifera L.), cagaiteira (Eugenia dysenterica DC.), araçá-boi (Eugenia stipitata McVaugh), ingá (Inga edulis Mart.), limão Tahiti (Citrus latifolia Tanaka) e acácia (Acacia mangium Willd.) (Junqueira, 1962; Mariconi, 1985; Couturier et al., 1999; Gallo et al., 2002; Silva, 2008; Arnhold \& Gonçalvez, 2010; Costa et al., 2011). 
No caso examinado, foi constatado que as folhas mais novas e a região apical das árvores atacadas apresentavam sinais de rendilhamentos, principalmente nas árvores de E. pellita e, em menor intensidade, nas de E. urophylla e de E. camaldulensis. Este resultado difere do reportado por Montes et al., (2012), que indicaram ataques mais intenso de C. ferruginea em E. urophylla; intermediário, em E. pellita e com menos injúria em E. camaldulensis, em plantio no município de Presidente Prudente, SP. No entanto, como os mecanismos de resistência de plantas a insetos são influenciados por fatores da própria planta (idade, parte infestada, fenologia, etc) e do inseto (densidade populacional, potencial biótico, genótipo etc) e, por fatores climáticos e edáficos (umidade, temperatura, pluviosidade, disponibilidade de nutrientes etc) (Lara, 1991; Marschalek, 2000; Bueno et al., 2006; Morais, 2009), genótipos de eucalipto cultivados em diferentes regiões tenderão a apresentar diferentes níveis de resistência ao ataque de pragas.

A região preferencial de ataque do inseto concorda com aquela identificada por Mendes et al., (1998), que relataram a preferência de $C$. ferruginea por brotos e partes apicais de eucalipto, o que pode causar perdas significativas do parênquima clorofiliano, prejudicando, assim, seu desenvolvimento. Segundo Montes et al., (2012), o desfolhamento do terço superior da copa, juntamente com o corte do ponteiro principal, pode implicar perdas de até $168,65 \mathrm{~m}^{3}$ de madeira por hectare.

Possivelmente, a preferência de $C$. ferruginea por espécies e híbridos de Eucalyptus se dê por características físico-químicas das folhas, como a presença de fagoestimulantes e de altos teores de nitrogênio (Ohmart et al., 1985). Além desses fatores, existem diferenças de compostos secundários das folhas das espécies de eucalipto, como taninos, outros compostos fenólicos, gorduras e óleos essenciais, que influenciam negativamente no processo de herbivoria (Ohmart \& Edwards, 1991).

Costalimaita ferruginea é uma espécie de besouro desfolhador com ampla distribuição geográfica, que só não havia sido constatada nos Estados do Acre e Tocantins (Mendes et al., 1998). Assim, graças a seu hábito polífago e a sua ampla ocorrência no Brasil, fazem-se necessários estudos sistemáticos de monitoramento, por parte dos silvicultores, a fim de permitir o registro e o posterior controle da infestação, quando no início (Lunz \& Azevedo, 2011). Além disso, considerando-se o uso de culturas agrícolas e florestais, hospedeiras de $C$. ferruginea, nos sistemas de integração lavoura-pecuária-floresta (ILPF), reforça-se a necessidade de extensivo monitoramento das infestações nessas áreas.

Em geral, surtos de besouros desfolhadores em eucaliptos são controlados com inseticidas piretroides (Costa et al., 2011), embora sinta-se ainda a ausência de pesqui- sas sobre o impacto ambiental dessas aplicações e até a do registro de produtos específicos para o controle de $C$. ferruginea em eucalipto (Agrofit, 2013; Lunz \& Azevedo, 2011). Portanto, essas pesquisas se fazem necessárias para se avaliarem inseticidas eficientes no controle desse besouro em cultivos de eucalipto. No entanto, independentemente do método de controle a ser adotado, é de fundamental importância conhecer a dinâmica populacional da praga-alvo e, se possível, obter informações sobre fatores bióticos e, ou, abióticos que influenciam suas populações (Costa et al., 2011), o que ajudaria na escolha de técnicas de manejo mais racionais e adequadas.

O registro de C. ferruginea no Estado do Acre contribui para o aumento do conhecimento da ocorrência e distribuição geográfica desse crisomelídeo, em plantios de eucalipto, na região amazônica, bem como no Brasil. Estudos sobre sua dinâmica populacional, sobre seus níveis de dano e sobre a resistência de espécies e híbridos de eucalipto ao ataque de $C$. ferruginea são recomendados, a fim de se traçarem estratégias de controle desse inseto no Estado.

\section{CONCLUSÕES}

O besouro-amarelo-do-eucalipto, Costalimaita ferruginea, encontra-se presente no Estado do Acre, associado a eucaliptais comerciais, sendo observado um ataque intenso em Eucalyptus pellita.

\section{REFERÊNCIAS}

Abraf (2012) Anuário estatístico da Associação Brasileira de Produtores de Florestas Plantadas 2012: ano base de 2011. Brasília, ABRAF. 150p.

Altieri MA, Silva EM \& Nicholls CI (2003) O papel da biodiversidade no manejo de pragas. Ribeirão Preto, Holos. 226p.

Agrofit (2013) Sistema de agrotóxicos fitossanitários. Disponível em <http://agrofit.agricultura.gov.br/agrofit_cons/ principal_agrofit_cons> Acessado em: 04 de setembro de 2015.

Arnhold A \& Gonçalves D (2010) Ocorrência de Costalimaita lurida (Coleoptera: Chrysomelidae) em Eucalyptus spp. em Minas Gerais. Pesquisa Florestal Brasileira, 30:257-259.

Bacha CJC \& Barros ALM (2004) Reflorestamento no Brasil: evolução recente e perspectivas para o futuro. Scientia Florestalis, 66:191-203.

Bueno LCS, Mendes ANG \& Carvalho SP (2006) Melhoramento genético de plantas: princípios e procedimentos. $2^{\mathrm{a}}$ ed. Lavras, Editora UFLA. 319p.

Costa EC, D'avila M, Cantarelli EB, Murari AB \& Manzoni CG (2011) Entomologia Florestal. $2^{\mathrm{a}}$ ed. Santa Maria, UFSM. 248p.

Couturier G, Müller CR, Silva AB \& Motta MM (1999) Insetos que atacam o camu-camuzeiro (Myrciaria dubia (H.B.K.) McVaugh, Myrtaceae) em cultivos paraenses. Belém, Embrapa Amazônia Oriental. 4p. (Comunicado técnico, 3).

Gallo D, Nakano O, Silveira-Neto S, Carvalho RPL, Baptista GC, Berti-Filho E, Parra JRP, Zucchi RA, Alves SB, Vendramim JD, Marchini LC, Lopes JRS \& Omoto C (2002) Manual de entomologia agrícola. Piracicaba, Fealq. 920p. 
Garlet J, Zauza EAV, Ferreira F \& Salvadori JR (2009) Danos provocados por coró-das-pastagens em plantas de eucalipto. Ciência Rural, 39:575-576.

Junqueira GM (1962) Nota sobre o "besouro amarelo dos eucaliptais”. O Biológico, 28:326-328.

Lara FM (1991) Princípios de resistência de plantas a insetos. $2^{a}$ ed. São Paulo, Editora Ícone. 336p.

Lunz AM \& Azevedo R de (2011) Caracterização da ocorrência do besouro-amarelo, Costalimaita ferruginea (Fabricius) (Coleoptera: Chrysomelidae), em plantios de Eucalipto no Pará. Belém, Embrapa Amazônia Oriental. 5p. (Comunicado técnico, 229).

Marschalek R (2000) Resistência genética a insetos em espécies florestais: revisão sobre o gênero Eucalyptus. Blumenau, Edifurb. $192 \mathrm{p}$.

Mariconi FAM (1985) Inseticidas e seu emprego no combate às pragas. São Paulo, Livraria Nobel. 466p.

Mendes JEP, Anjos N \& Camargo FRA (1998) Monitoramento do besouro-amarelo. Folha Florestal, 91:08-09.

Montes SMNM, Sato ME \& Cerávolo LC (2012) Avaliação de danos de adultos de Costalimaita ferruginea (Fabricius) (Col.: Chrysomelidae) em Eucalyptus spp. de Presidente Prudente, SP. Arquivos do Instituto Biológico, 79:431-435.

Morais LAS (2009) Influência dos fatores abióticos na composição química dos óleos essenciais. Horticultura Brasileira, 27:4050-4063.
Ohmart CP, Stewart LG \& Thomas JR (1985) Effects of food quality, particularly nitrogen concentrations, of Eucalyptus blakelyi on the growth of Parapsis atomaria (Coleoptera: Chrysomelidae). Oecologia, 65:543-549.

Ohmart CP \& Edwards PB (1991) Insect herbivory on Eucalyptus. Annual Review of Entomology, 36:637-657.

Panizzi AR \& Parra JRP (2009) Bioecologia e nutrição de insetos: base para o manejo integrado de pragas. In: Panizzi AR \& Parra JRP (Eds.) Introdução à bioecologia e nutrição de insetos como base para o manejo integrado de pragas. Brasília, Embrapa Informação Tecnológica. 164p.

Santos GP, Zanuncio JC, Zanuncio TV \& Pires EM (2008) Pragas do eucalipto. Informe Agropecuário, 29:47-70.

Silva WR, Marsaro Júnior AL, Pereira PRVS, Sousa ASR \& Griffel SCP (2008) Levantamento de hospedeiros de Costalimaita ferruginea (Coleoptera: Chrysomelidae) em Roraima. In: $22^{\circ}$ Congresso Brasileiro de Entomologia: Ciência, Tecnologia e Inovação, Uberlândia. Anais, UFV/UFU/EMBRAPA CNPMS. p. 901.

Zanuncio JC, Bragança MAL, Laranjeiro AJ \& Fagundes M (1993) Coleopteros associados à eucaliptocultura nas regiões de São Mateus e Aracruz, Espírito Santo. Revista Ceres, 4:584-590. 